\title{
Polygenic control of an all-or-none morphological trait in Euplotes (Ciliata, Hypotrichea). Evolutionary significance of naturally occurring morphological variation in Ciliates
}

\author{
J Génermont *, C Demar, G Fryd-Versavel, H Tuffrau, M Tuffrau \\ Université de Paris-Sud, Laboratoire de Biologie Evolutive et Dynamique des \\ Populations, Bât 446, 91405 Orsay Cedex, France
}

(Received 7 October 1991 ; accepted 30 January 1992)

\begin{abstract}
Summary - A hereditary abnormality is described in Euplotes crassus, consisting of disturbances of the ventral somatic ciliary pattern, as a result of alterations of the development of primordia of frontoventral and transverse cirri. A breeding analysis was performed, the results of which are not consistent with monofactorial Mendelian determination, thus permitting the consideration of an alternative hypothesis of polygenic control. From a survey of presently known spontaneously occurring variants in Ciliates, it is inferred that some apparently minor changes which take place in the course of morphological divergence between related species probably cannot be accounted for by fixation of a low number of mutations, but require some more complex genetic repatterning.
\end{abstract}

ciliary pattern / Euplotes / polygenic inheritance / speciation / threshold character

Résumé - Déterminisme polygénique d'un caractère morphologique tout-ou-rien chez Euplotes (Ciliés Hypotriches). Signification évolutive de la variabilité morphologique naturelle chez les Ciliés. Un clone présentant une anomalie morphologique a été isolé d'une population de laboratoire constituée en vue de perpétuer une importante variabilité génétique. Sur les cellules végétatives le nombre de cirres occupant l'emplacement normal des transverses est inférieur au nombre standard de 5, tandis que des cirres sont disposés de façon désordonnée dans la partie postérieure de la zone fronto-ventrale. L'étude de la morphogenèse de division montre que les primordiums communs aux cirres transverses et fronto-ventraux se forment normalement, mais qu'ils présentent des altérations lors de

\footnotetext{
* Correspondence and reprints
} 
leur fragmentation en ébauches de cirres et surtout que le positionnement des ébauches postérieures est anarchique.

Le croisement du clone anormal avec un clone normal issu de la même population fournissant une $F_{1}$ normale, l'hypothèse d'un déterminisme monofactoriel récessif de l'anomalie pouvait être émise. La descendance d'un back-cross, puis celles de plusieurs croisements n'ont pas les compositions attendues sous cette hypothèse, même en admettant que des écarts aux proportions mendéliennes puissent être introduits soit du fait de la mortalité à laquelle sont sujets les clones anormaux à l'issue de la conjugaison, soit du fait de la mise en jeu de phénomènes d'hérédité caryonidale comme on en connaît par ailleurs chez les Ciliés. En conclusion, l'anomalie, qui, à l'échelle du clone, obéit à la règle du tout-ou-rien, apparaît comme un caractère à seuil, à déterminisme polygénique.

D'un survol des différents types de variants morphologiques connus chez les Ciliés, et notamment de ceux qui ont été obtenus sans application d'un traitement mutagène, il ressort que ces variants diffèrent en général bien plus du «standard» de leur espèce que ne diffèrent de celui-ci d'autres espèces du même genre. En particulier, la variation sur des caractères apparemment aussi mineurs que la présence ou l'absence d'un cirre est strictement interspécifique. Elle met en jeu, contrairement à ce qu'on aurait pu prévoir, d'importants remaniements génétiques, sans commune mesure avec la très faible divergence observée entre les espèces jumelles.

caractère à seuil / ciliature / Euplotes / hérédité polygénique / spéciation

\section{INTRODUCTION}

In Euplotes, some morphological features are highly conserved throughout the evolutionary diversification of the genus. Such is the case for the general pattern of the somatic ventral ciliature. It is composed of cirri which are usually classified in 3 groups on the basis of their morphological arrangement in vegetative cells (fig 1). The frontoventral cirri (FV) are distributed on the anterior right quarter of the ventral area; their number and their topological relationships are very stable within a species. The transverse cirri $(T)$ are attached to the ventral surface along a V-shaped subequatorial line; their number is 5 in all species but one ( $E$ strelkovi Agamaliev). The caudal cirri (usually 4 to 6 ) lie very close to the posterior margin of the cell.

This classification is no longer valid when morphogenesis is taken into consideration (fig 2). One of the FVs is obviously related to the oral ciliature: it may be referred to either as the buccal (Borror, 1972) or as the paroral (Tuffrau et al, 1976) cirrus. All other FVs and Ts originate from a set of 5 primordia, each one consisting of a longitudinal streak of kinetosomes which elongates, then fragments into 2 or 3 cirral anlagen: the Ts emerge from the 5 posterior anlagen and the FVs (except for the buccal cirrus) from the others. In those species, such as $E$ crassus, which possess $10 \mathrm{FVs}, 3$ cirral anlagen are derived from each primordium, except for the most marginal one (at the right end of the set) which generates only 2 anlagen. All cirri developed from this set of 5 primordia make up a morphogenetical unit which will be referred to in the present paper as the FVT complex, a denomination which is not a synonym of the FVT system introduced by Gates (1987b), since the latter includes the buccal cirrus. As for caudal cirri, they belong to 2 separate groups, 


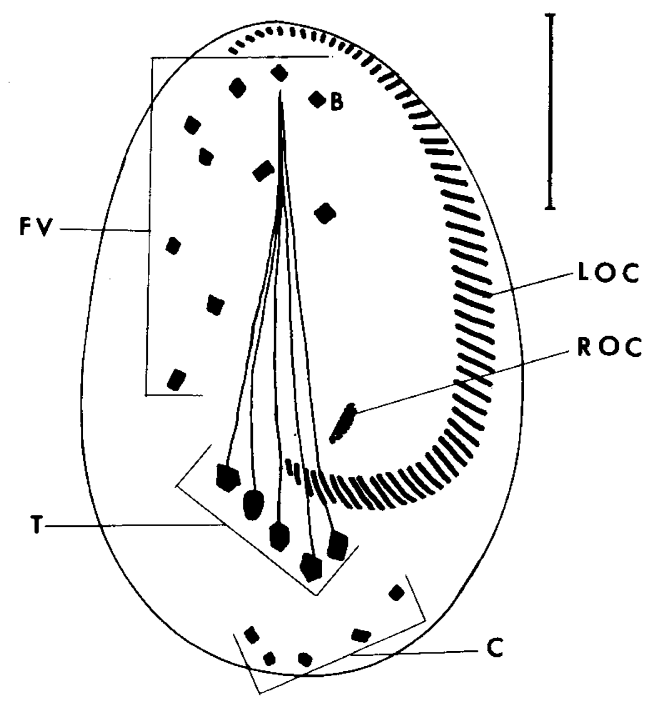

Fig 1. Semidiagrammatic representation of the ventral surface of a wild-type cell in the vannus group of the genus Euplotes. LOC, ROC: left and right components of oral ciliature. FV, T, C: frontoventral, transverse and caudal cirri. One of the frontoventral cirri is referred to as the buccal cirrus, B (for further explanations, see text and fig 2). Long ascendant subpellicular fibres are associated with transverse cirri. The vertical bar indicates $30 \mu \mathrm{m}$.

since 2 of them originate from a primordium located on the left side of the ventral area whereas the others are related to the dorsal kineties.

By mixing many conspecific clones collected from a large array of stations, a synthetic population was established, then maintained in the laboratory in such a way that sexual processes were expected to occur repeatedly. Later, a few new clones were occasionally added, so that a significant level of genetic diversity was likely to be present in the population some years after its foundation. Many clones were isolated from this synthetic population in order to carry out an experimental study of heritable variation for some morphological traits. Under cytological examination, one of these clones, here referred to as $G_{0}$, proved to include a rather high proportion (about $50 \%$ ) of cells in which the FVT pattern was severely disturbed: such cells are referred to as fvtd cells.

A study of such a variant trait is expected to provide some insight into understanding the mechanisms by which cirral anlagen positioning is achieved, especially if it is single-gene determined. On the other hand, from an evolutionary point of view, it is of some interest to appreciate to what extent naturally occurring intraspecific morphological variation is related to interspecific variation. Thus an experimental study was designed in order to elucidate the genetic control of the fvtd phenotype. We report here the main results of this study, together with a brief description of the variant phenotype itself. A more detailed account of the morphological features and morphogenetical events will be published elsewhere. 


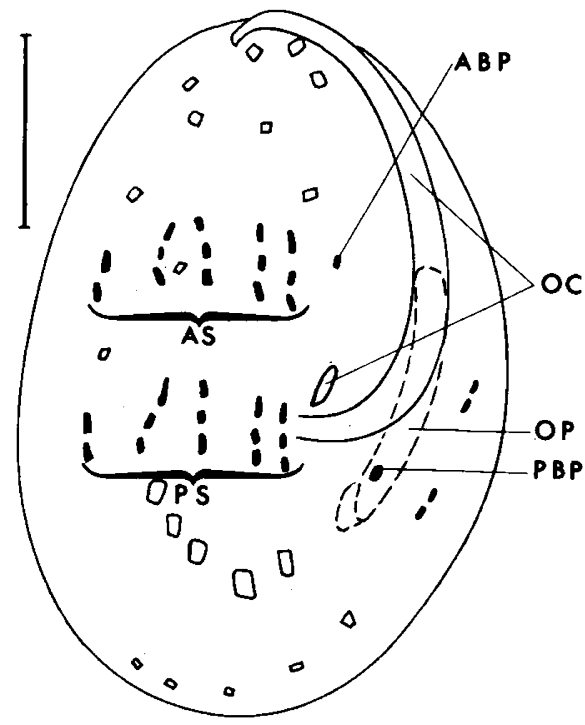

Fig 2. Prefission morphogenesis of the ventral ciliature in a wild type cell. All cirri of the mother cell (represented by the outlines of their basal plates) disintegrate. The old oral ciliature (OC) will be retained by the anterior daughter cell. For the posterior daughter, a new oral apparatus emerges from a single oral primordium (OP) which segregates the primordium of the buccal cirrus (PBP). The buccal cirrus of the anterior cell originates from a specific primordium (ABP) which is initiated in close association with the right component of the old oral apparatus. The other frontoventral and transverse cirri arise from 2 sets, respectively anterior (AS) and posterior (PS), of 5 longitudinal streaks of kinetosomes. At the stage represented here, each of these streaks is being fragmented into either 2 or 3 cirral anlagen (drawn as black spots). Close to the left margin of the ventral area, ie at the observer's right, 2 primordia will yield one group of 2 caudal cirri in each daughter cell.

\section{MATERIAL AND METHODS}

The "abnormal" clone belongs to a species which in previous publications has been referred to as "species No 2 of the Euplotes vannus complex" (Génermont et al, 1976, 1985; Machelon et al, 1984). However, the proper name is $E$ crassus rather than $E$ vannus (see Discussion).

The cultures are grown at room temperature on dried lettuce infusion prepared with natural sea water (obtained from the Laboratoire Maritime, Luc sur Mer, France), sterilized, then inoculated with Enterobacter aerogenes.

Crosses were achieved by mixing samples of 2 complementary clones, in the maturity period of the life-cycle, grown in test tubes up to exhaustion of culture medium in order to induce sexual reactivity. A few hours later, pairs of presumptive conjugants could be isolated, then next day presumptive exconjugants. We retained only the cells which satisfied the following 3 criteria: i), regression of buccal structures; ii), development of a large discoid macronuclear anlage; iii), no fission during the first 3 days following separation of mates. These criteria ensure that a 
true sexual process is completed. Cytogamy or selfing would be excluded only on the basis of the hereditary transmission of marker genes. No such genes were identified in our material, except for the mating type determining series of alleles (Heckmann, 1964) which provided rather poor information, since in the whole course of our breeding analysis only 2 mating types were present, segregating in a 1:1 fashion in any cross. No significant departure from this ratio was ever observed, and no clone was detected exhibiting a third mating type, so that there is no evidence against the idea that the isolated cells were true exconjugants. Moreover, we know from previous extensive work that in our experimental conditions selfing and cytogamy are highly exceptional in intraspecific sexual reactions in the $E$ crassus complex.

For cytological examination under light microscope, silver impregnation was performed as adapted from Chatton and Lwoff (1930) by Frankel and Heckman (1968) and protargol staining was carried out according to the procedure devised by Tuffrau (1967), slightly modified by using the slowly acting developer recommended by Foley (1943).

For rapid screening of clones in the course of breeding analysis, "ghosts" were obtained by means of detergent treatment. Cells from a culture sample were collected by low-speed centrifugation, then suspended for $10 \mathrm{~min}$ in a $2 \%$ Nonidet $\mathrm{P} 40^{\circledR}$ solution in PHEM buffer (Schliwa and Van Blerkom, 1981). After washing with PHEM and centrifugation, the ghost pellet was deposited on a microscope slide, gently compressed with a cover-glass and observed with phase optics. The cirral pattern of about 20 ghosts was ascertained. Most clones fell clearly into one or other of 2 discrete classes: those in which the frequency of fvtd was close to $100 \%$, referred to as futd clones, and those in which all cells were normal, referred to as wt (wild-type). A few clones remained unclassified since the sample included a mixture of fvtd and normal cells; they were further characterized on the basis of standard protargol staining; they were proven to include at least $30-40 \%$ fvtd cells, and were therefore classified as futd clones.

\section{RESULTS}

\section{The futd phenotype}

The most prominent and constant feature of the fvtd phenotype is the presence of fewer than 5 cirri in the usual place of the Ts. However, it cannot be described as the loss of some transverse cirri, as revealed by the sequence of morphogenetic events resulting in the abnormal pattern (fig 3 ).

During prefission morphogenesis, the 5 primordia which are expected to yield the FVT complex seem to be quite normal in both location of initial sites and early stages of elongation of kinetosome streaks. Later, in the course of further elongation and thickening of the streaks, some irregularities are observed, such as breaks or branching resulting in extra primordia. Still later, some cirral anlagen, especially the posterior ones in each daughter cell migrate in a more or less random fashion and a few eventually disintegrate. Finally the number of FVT cirri may be either higher or lower than the standard number of 14 and some of them, including one or several "presumptive Ts", are mispositioned. Some of the mispositioned Ts can be unequivocally identified in vegetative cells, since they retain their association with 


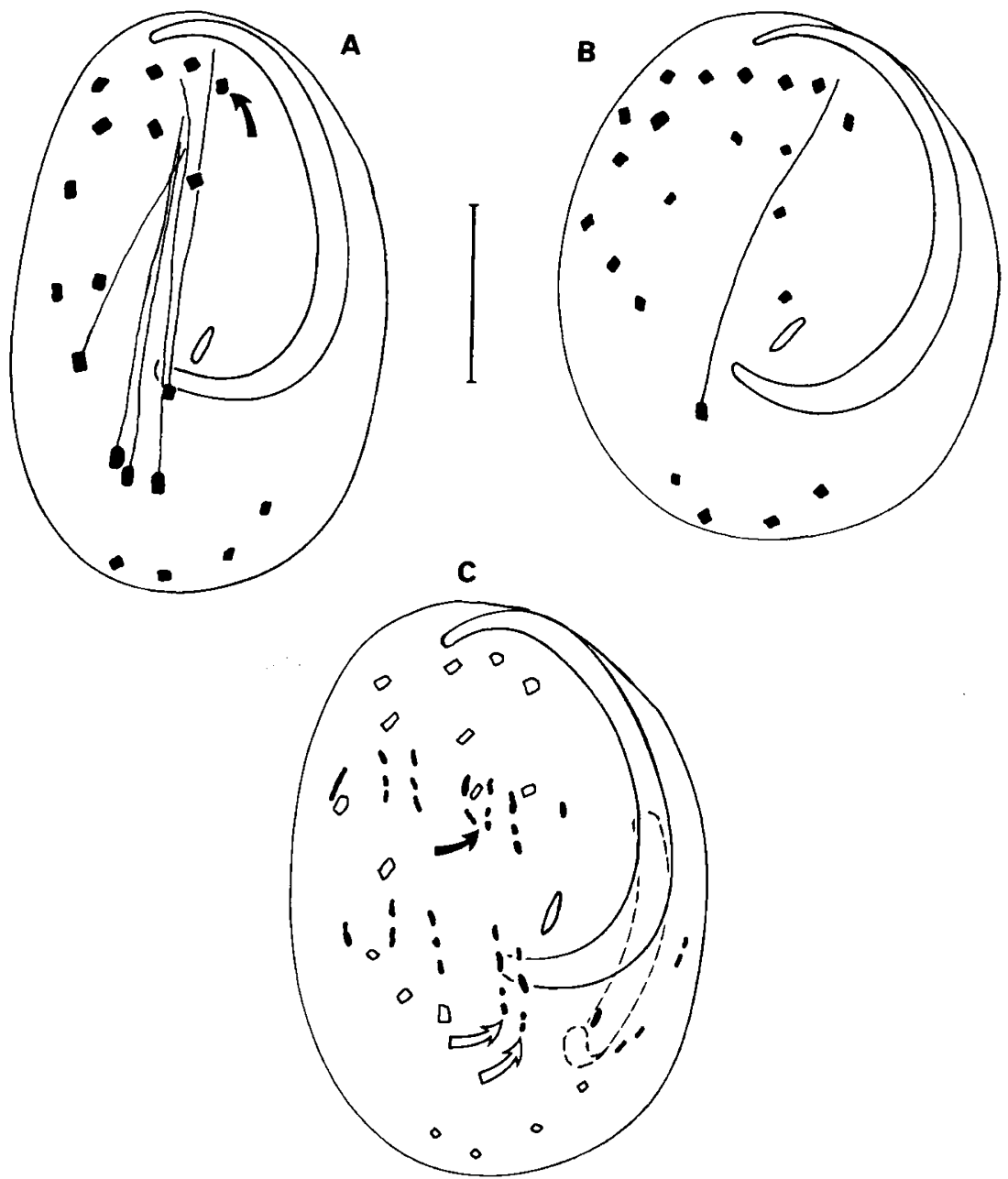

Fig 3. The fvtd phenotype. A, A slightly altered fvtd cell. Five cirri are readily identified as transverse on the basis of their association with long ascendant subpellicular fibres. The FVT complex includes 14 cirri, ie the normal number; however, the geometrical arrangement of the 7 posterior ones is somewhat anarchical (compare to fig 1 ). The arrow indicates the buccal cirrus, which does not belong to the FVT complex. B, A more extreme fvtd cell. Only one cirrus may be identified as a transverse one. The FVT complex includes 17 cirri, distributed apparently at random, at least for the most posterior ones. Some of them have very small basal plates. $C$, Prefission morphogenesis in a fvtd cell. The anterior set of FVT primordia includes 6 primordia (instead of 5), presumably as a consequence of branching of one of the 5 primary primordia (black arrow). In the posterior set, 2 primordia are being fragmented into 4 anlagen instead of 3 (open arrows). 
long ascendant subpellicular fibres, a feature which is known as strictly T-specific in wild-type.

\section{Breeding analysis}

\section{Preliminary observations}

The fvtd condition is inherited through asexual multiplication: when cells were reisolated from the $G_{0}$ clone, at clonal ages exceeding 100 fissions, they yielded subclones all of which exhibited the fvtd condition at the same level, ie the frequency of fvtd cells was close to $50 \%$.

\section{First crossing experiment}

The $G_{0}$ clone was crossed to another clone, isolated from the same synthetic laboratory population and selected on the basis of exhibiting the wt condition and sexual compatibility to $G_{0}$. From this cross, 24 conjugating pairs were isolated and the 48 exconjugants were separated. Out of these 48 cells, 35 yielded viable clones, making up the $G_{1}$ generation. The mortality rate following conjugation is thus $13 / 48=0.27$, a figure which falls within the range of usually observed values in this species. All $G_{1}$ clones were undoubtedly wt.

\section{Second crossing experiment}

Among the $G_{1}$ clones, at clonal ages estimated at about 60 fissions, 9 were found to be sexually compatible with $G_{0}$, so that they could be backcrossed to their apparently recessive parent. From each of the 9 backcrosses, 12 exconjugants (derived from 12 different mating pairs) were isolated. From a total of 108 exconjugants, 46 viable clones ( $G_{2}$ generation) were recovered (table I). Among them, 7 are unambiguously classified as fvtd and 39 as wt. The viable clones and the futd clones seem to be evenly distributed among the 9 progenies.

Table I. Distribution of the fvtd $v s$ wt condition within the progenies of 9 back-crosses between $9 F_{1}$ clones and $G_{0}$ ( $R$, number of clones recovered from 12 exconjugants).

\begin{tabular}{lccc}
\hline No & $R$ & fvtd & $w t$ \\
\hline 1 & 6 & 1 & 5 \\
2 & 5 & 0 & 5 \\
3 & 5 & 1 & 4 \\
4 & 6 & 1 & 5 \\
5 & 4 & 0 & 4 \\
6 & 4 & 0 & 4 \\
7 & 3 & 2 & 5 \\
8 & 6 & 1 & 6 \\
9 & 7 & 1 & 39 \\
Sum & 46 & 7 & \\
\hline
\end{tabular}


The fvtd/wt segregation is apparently quite different from the 1:1 ratio expected if the fvtd condition is determined by a single recessive allele. However, some attention must be paid to the rather high mortality rate: 0.57 , significantly higher than the $G_{1}$ figure. Two different phenomena, which are not mutually exclusive, may account for this: inbreeding depression (under the assumption that the 2 parental clones were neither inbred nor related, the $G_{1}$ clones are not inbred, but in any $G_{2}$ clone the inbreeding coefficient is $1 / 4$ ) and positive association between the futd condition and lower ability to overcome the critical early stages of clonal life. The observed results are actually not very different from those that would be expected on the basis of a 1:1 ratio of futd to wt clones, combined with mortality rates close to 0.15 among wt clones and 0.85 among fvtd ones.

\section{Third crossing experiment}

If the "single gene hypothesis" is true, all fvtd $G_{2}$ clones are homozygous for the recessive allele which determines the fvtd condition, so that any cross between 2 of these clones must yield similarly homozygous, uniformly futd, progeny. It was thus planned to cross the fvtd $G_{2}$ clones in all possible combinations. Actually, among these 7 clones, one (belonging to the progeny of backcross No 7) could not be brought to mating reactivity. Among the 6 reactive ones, 2 mating-types were found, allowing 8 crosses. Unfortunately, the reactivity of one of the clones was very weak, as a consequence of premature senescence (at the time of the experiment, the clonal age was about 100 fissions, within the usual maturity period) so that the effective number of progenies making up the $G_{3}$ generation was 6 . The results are given in table II. Two sets of conclusions can be drawn.

Table II. Progenies of the 8 crosses yielding generation $G_{3}$. For each one, from left to right: number of futd clones, number of viable exconjugant clones, number of isolated exconjugants.

\begin{tabular}{ccccc}
\hline & 1 & 3 & 7 & 9 \\
\hline 4 & $2: 3: 52$ & $9: 19: 50$ & $4: 6: 60$ & $0: 0: 12$ \\
8 & $1: 3: 34$ & $0: 1: 60$ & $0: 0: 60$ & $0: 0: 0$ \\
\hline
\end{tabular}

First, the overall mortality is impressively high: about $90 \%$. It does not seem possible that inbreeding could account for this: the inbreeding coefficient of $G_{3}$ clones is $5 / 16$, not substantially larger than in $G_{2}$. Moreover, the mortality rates are very different among separate progenies: from 0.6 in cross $3 \times 4$ to 1.0 in cross $7 \times 8$, despite strictly identical levels of inbreeding. On the other hand, the 5 clones which yielded $G_{3}$ were obviously fully mature, so that the postconjugation mortality is not attributable to parental senescence. These results support the idea, expressed above, of an association between the fvtd condition and mortality.

The second set of conclusions concerns the futd condition itself. It is expressed in 16 out of 32 viable $G_{3}$ clones. This result seems to be in strong disagreement with the single-gene hypothesis. However, it cannot be excluded that so-called caryonidal inheritance would interact with a Mendelian mechanism. According 
to such a hypothesis, all of the $32 G_{3}$ clones would be homozygous for the fvtd determining recessive allele, but in 16 of them the macronuclei would have lost the ability to express it. It is actually known that in Ciliates the expression of some characters is conditioned by some switch which occurs when, in late stages of sexual phenomena, the macronucleus develops from a micronucleus: these characters have been reviewed by Sonneborn (1977).

\section{Fourth crossing experiment}

If all $G_{3}$ clones are homozygous for a fvtd determining allele, they must transmit it through conjugation, irrespective of their expressed phenotype. All progenies of $G_{3} \times G_{3}$ crosses (either fvtd $\times$ fvtd, or fvtd $\times$ wt or wt $\times$ wt) are thus expected to be similar.

Many crosses between sexually compatible $G_{3}$ clones were carried out. The $G_{4}$ clones were classified according to the types expressed by the 2 parents. The overall results are given in table III. From these results the probability of displaying the futd condition may be estimated for a clone when both parents are futd $(13 / 29=0.45)$, when only one parent is fvtd $(37 / 156=0.24)$, or when both parents are wt $(4 / 87=0.05)$. These 3 figures are very different, so that the results do not support the single-gene hypothesis. It is not strictly excluded, since some situations are known in which caryonidal inheritance allows some parent-offspring correlation, for instance the B system of mating type determination (Sonneborn, 1937) and resistance to $\mathrm{CaCl}_{2}$ (Génermont, 1961) in Paramecium. However, it is highly unlikely, so that it is strongly suspected that some alternative hypothesis should fit the whole set of experimental data.

Table III. Generation $G_{4}(N$, number of isolated exconjugants; $R$, number of viable clones recovered; $n a$, not ascertained).

\begin{tabular}{ccrrrrr}
\hline Type of cross & $N$ & $R$ & fvtd & wt & $n a$ \\
\hline fvtd $\times$ fvtd & 237 & 30 & 13 & 16 & 1 \\
futd $\times$ wt & 529 & 178 & 37 & 119 & 22 \\
wt $\times$ wt & 420 & 96 & 4 & 83 & 9 \\
\hline
\end{tabular}

\section{DISCUSSION}

\section{Genetic control of the fvtd trait and associated mortality}

According to the above results, it is very unlikely that the fvtd condition depends on a single recessive allele. That it depends on recessive alleles at 2 different loci is still more unlikely. Other models involving 2 loci do not fit our data satisfactorily. It is thus proposed that the genetic control of the futd $v s$ wt binary variate is polygenic. Though the model of polygenic inheritance was initially developed with respect to continuous variation, it was later shown that it could be applied to 
categorical data (Wright, 1934a, 1934b). This model seems to fit very well to the results obtained in the present study, especially for the $G_{4}$ generation in which a good positive correlation appears between the probability for a clone to display the fvtd condition and the number of its fvtd parents.

It can be questioned if the fvtd condition is a true all-or-none character. Actually it is clear that some of the clones which have been classified as fvtd are somewhat intermediate, since they include both fvtd and normal cells: such was the case of the $G_{0}$ clone. These observations could suggest a study of the frequency of fvtd cells within a clone as a quantitative continuous character. Though we did not collect extensive data, it became obvious that this character was not suitable for quantitative analysis, since most clones are phenotypically uniform; so, it was arbitrarily chosen to classify the few intermediate clones, the frequency of which is very low (less than $5 \%$ ), as futd.

Concerning mortality rates, the experimental data which have been accumulated for some 15 years support the idea that the species of the Euplotes crassus complex are outbreeders in natural conditions and that inbreeding often results in an increase of the frequency of inviable exconjugants. It is thus likely that the high mortality rates which have been observed in the course of the present work are to some extent accounted for by inbreeding depression. However, the very high mortality rate of the $G_{3}$ generation needs some further explanation. As suggested above, it may be assumed that the fvtd condition favours exconjugant inviability, more or less irrespective of the inbreeding level. Thus, in most experiments the overall mortality rate is the joint effect of the 2 causes.

If this interpretation is correct, at a given inbreeding level, a positive correlation is expected between mortality rate and frequency of fvtd clones. The results obtained in $G_{4}$ are not inconsistent with this idea, since $G_{4}$ includes clones of very different inbreeding levels. On the other hand, it must be pointed out that at any generation the fvtd $v s$ wt ratios are biased: fvtd frequencies are systematically underestimated.

In any breeding experiment, the observed ratios express the interactions of at least 3 kinds of phenomena: segregation of a polygenic system, inbreeding associated mortality, and fvtd associated mortality. Because of the complexity of such interactions, any attempt to estimate genetic parameters (heritability, for instance) would be unfounded.

\section{Genetic control of all-or-none traits}

As far as we know, no all-or-none qualitative trait has been reported to date as polygenically determined in Ciliates, since the only suggestion of polygenic inheritance of morphological characters deals with the number of dorsal ciliary rows (Frankel, 1973b). It must be pointed out that in some instances erroneous conclusions might be drawn from segregation data. This is well exemplified by results obtained by Wright (1934b) in the course of his study of polydactyly in the guinea pig. When a polydactyl and a normal line were crossed, the $F_{1}$ was uniformly normal. The backcross and $F_{2}$ results show no significant departure from the classical Mendelian ratios of 1:1 and 3:1, respectively. Thus the assumption that polydactyly was controlled by a single recessive allele seemed to be strongly supported. However, it was ruled out on the basis of results obtained in the third 
generation, since relatively large numbers of normal animals were recovered from crosses between presumed homozygous recessives. The final conclusion was that polydactyly was a so-called threshold character under polygenic control.

From a survey of the literature dealing with genetics of morphological traits in Ciliates, it appears that 3 previously described variants display some similarities to fvtd: not induced by any mutagenic treatment and including alterations of the assembly and positioning of kinetosomes in the course of completion of the overall ciliary pattern of the cell. These 3 are the $\mathrm{mlm}$ (multileft-marginal) variant of Paraurostyla weissei, the mp (membranellar pattern) variant of Tetrahymena thermophila, and the bbd (basal body deficient) variant of Euplotes minuta. Since they had been claimed to be single-gene determined, we reexamined the segregation data on which these assumptions had been founded.

In mlm clones, most cells possess 2 or 3 left marginal rows of cirri, instead of 1 in the wild-type condition. The early stages of prefission morphogenesis look quite normal, such as in the fvtd situation. The alteration is initiated by the segmentation of the presumptive primordium of the left marginal row, a single kinetosomal streak; the segments become parallel to each other and each one develops into a row of cirri (Jerka-Dziadosz and Banaczyk, 1983; Dubielecka and Jerka-Dziadosz, 1989). All known mlm lines are inbred clones derived from 2 exconjugants isolated from a sample collected from a single pond. They have been pedigreed over 10 generations. The progenies of 3 crosses have been screened for segregation of the mlm trait. Both pedigree and segregation data strongly suggest a single-gene control (JerkaDziadosz and Dubielecka, 1985), so that this hypothesis may be held as rather firmly established, in spite of lack of direct evidence of homozygosity of mim clones, since no viable progeny could be recovered from $\mathrm{mlm} \times \mathrm{mlm}$ crosses. It must be added that some clones have been found which exhibited a somewhat enhanced mlm phenotype; it is likely that they are homozygous not only for the mlm mutation itself, but also for a recessive allele at another locus (Jerka-Dziadosz, 1989; JerkaDziadosz et al, 1989).

The mp phenotype was discovered in a laboratory inbred line. It consists of some alterations in the development of the oral apparatus, especially during oral replacement, a process which usually occurs in starved cells, so that the frequency of abnormal cells in a growing culture is rather low and increases up to $80 \%$ when the stationary phase is reached. During oral replacement in a wild-type cell, an oral primordium arises from the fusion of 2 kinetosome fields, one of which is associated with the old disintegrating oral apparatus and the other related to the so-called stomatogenic ciliary row. Later, the patterning of the single anarchic field results in the differentiation of the components of the new oral apparatus, which includes 3 membranelles. Conversely, in $\mathrm{mp}$ cells the fusion of the 2 initial fields is delayed and each one differentiates 3 membranellar anlagen. Later, the 6 anlagen are incorporated into a single oral apparatus, and some of them fuse in such a way that the final number of membranelles is usually 4 or 5 (Kaczanowski, 1975). The mp line was crossed to a wild-type line. The observed segregation fit the expected ratios, 1:1 for back-cross and 1:2:1 in $F_{2}$, under the assumption that the mp phenotype is controlled by a single recessive allele. The $F_{2}$ clones which were classified as homozygous recessive included in stationary phase 40 to $60 \% \mathrm{mp}$ cells, frequencies rather lower than those which were reported for the parental $\mathrm{mp}$ line. 
About $50 \%$ of the $F_{2}$ clones appeared to be phenotypically normal during early stages of clonal life, but later produced mp cells at low frequencies ( 1 to $10 \%)$ : they were interpreted as heterozygous, segregating phenotypically $\mathrm{mp}$ sublines by means of phenotypic assortment, a phenomenon which is well documented in Tetrahymena thermophila (Sonneborn, 1974; Orias and Flacks, 1975), but which was not checked in this particular situation. The main difficulties for the single gene hypothesis arise from the occurrence of $2 F_{1}$ clones which proved to be phenotypically mp and not to segregate wild-type progeny clones by backcrossing or by intercrossing. Kaczanowski (1975) pointed out that these unexpected results might deserve some further attention, but he nevertheless did not rule out the single gene hypothesis. In our opinion, these results indicate that the genetic control of the mp genotype is presumably more complex than first assumed. Among a large range of hypotheses, a polygenic system is not excluded.

In the bbd variant of Euplotes minuta, the primary defect seems to be a failure to produce new basal bodies in prefission stages of morphogenesis. Some of the resulting abnormalities of the ciliary pattern can be interpreted as direct consequences of this defect: loss of dorsal ciliary rows, lack of 1 or 2 right caudal cirri, presence of a few incomplete membranelles. Some others cannot be explained in this simple way: for instance, during proliferation of basal bodies within a given ciliary row, a few basal bodies may become mispositioned and then initiate a new row, parallel to the preexisting one. Thus there are 2 opposite tendencies during the growth of a bbd clone, one to loss, the other to addition of ciliary rows, so that the intraclonal variability for the number of rows is much higher in bbd than in normal clones. The rather complex bbd phenotype is very likely to be controlled by a single recessive allele (Frankel, 1973a).

Thus if our interpretation is correct, fvtd is the only variant of ciliary pattern for which the breeding data are strongly suggestive of polygenic inheritance.

\section{Morphological variants and evolution}

If $E$ balticus is excluded, since the information available on this taxon is very poor, the section A of the genus Euplotes, as defined by Curds (1975), is very likely to be monophyletic on the basis of many similarities in ciliary patterns and arrangement of the dorsal argyrome (Tuffrau, 1960; Curds, 1975; Gates, 1978a, 1978b), mating type systems (Heckmann, 1963, 1964; Nobili, 1966; Wichterman, 1967), electrophoretic patterns (Schlegel et al, 1988), habitat, etc. Since the oldest specific epithet applying to a category included in this section is vannus (Müller, 1786), this valid infrageneric taxon may be conveniently referred to as "the vannus group of genus Euplotes" (Génermont et al, 1985). Within it, 3 entities can be separated on the basis of morphometric, biochemical and ecological criteria (Machelon et al, 1984; Génermont et al, 1985; Valbonesi et al, 1988; Gianni and Piras, 1990). Since the 3 kinds of criteria provide arguments in very good agreement with each other, it may reasonably be assumed that these entities are monophyletic taxonomic units. They are obviously rather closely related, since mating reactions have been observed between members of different units (Nobili, 1964). Genetic exchanges are nevertheless impossible, so that the taxonomic level of these entities is either specific or supraspecific. Morphometric studies failed to detect any unambiguous clustering of populations at a lower level, so that these 
entities may be referred to as morphotypes. It has been repeatedly pointed out that these morphotypes satisfactorily fit earlier diagnoses of Euplotes vannus $\mathrm{O} F$ $M$ (long and relatively straight cells), $E$ crassus Dujardin (shorter and relatively wider) and $E$ minuta (definitely smaller): for a thorough discussion, see for instance Valbonesi et al (1988) and Schlegel et al (1988).

One of these morphotypes has been proved to be a complex of several (at least 5) sibling species: it was "provisionally" named "Euplotes vannus complex" (Génermont et al, 1976, 1985; Machelon et al, 1984). In the light of present knowledge, it is clear that this complex is actually identical to the $E$ crassus morphotype, so that it must be renamed "Euplotes crassus" complex. Thus the species in which the fvtd trait is reported in the present paper is conveniently referred to as $E$ crassus, species $\mathrm{No} 2$.

The species of the $E$ crassus complex are highly similar at the morphological level, and also at the electrophoretic and ecological levels (Machelon et al, 1984 and unpublished results), so that it may be suggested that the speciation events which promote an increase in the number of species within the complex result from a more or less random accidental rise of mating barriers, with very little evolutionary importance. Some equilibrium must be reached between speciation and extinction rates with minor ecological consequences, so that the effective evolutionary unit is not the species, but the complex itself. Thus the evolutionary significance of the $E$ crassus complex is very different from that of some other complexes of sibling species, for instance Paramecium aurelia (Sonneborn, 1975) in which the ecological niches are only partly overlapping.

More important from an evolutionary point of view is the differentiation of the 3 morphotypes, crassus, vannus and minuta. At a morphological level, crassus and vannus seem more similar to each other than either of them to minuta. Formally, it seems that it would be possible to transform crassus into vannus by increasing cell length, decreasing cell width and decreasing the number of dorsal ciliary rows. Since intraspecific genetically determined naturally occurring variation is known for the number of ciliary rows (Heckmann and Frankel, 1968; Frankel, 1973b; Laloë, 1979), and a positive correlation has been shown between number of rows and cell width (Machelon et al, 1984), it could be expected that some progress towards the vannus phenotype would be obtained by selecting for a high length/width ratio in a genetically heterogeneous population of the crassus morphotype. Such an experiment was carried out over 5 sexual generations, starting from the species No 2 synthetic population described above. Unexpectedly, despite a rather strong selection pressure, no response was observed (unpublished results).

On the other hand, there are some indications that the loss of one of the FV cirri might have occurred several times independently during the evolutionary diversification of the genus (Schlegel et al, 1988). It may be postulated that such a minor change involves the fixation, associated with some speciation event, of a very low number of mutations, perhaps a single one. If this is true, it should be possible to find, by means of an extensive survey of intraspecific variation, some exceptional variants, genetically determined, differing from the species standard pattern by lacking one cirrus. Such variants have not been found, either naturally occurring or induced by mutagenic treatment. It cannot be excluded, of course, that more extensive studies would result in their discovery. 
More generally, however, those variants which have been isolated usually exhibit very large deviations from the standard ciliary patterns, much larger than interspecific differences within a genus. The futd cells which are shown in fig $2 \mathrm{~A}$ and 2B display a non-Euplotes cirral pattern. The mlm mutant of Paraurostyla weissei shows profound alterations in some morphogenetic fields. The membranellar pattern of the $\mathrm{mp}$ variant in Tetrahymena thermophila is unstable. In the bbd variant of Euplotes minuta, the phenotype is by no means reminiscent of the standard pattern of any related species. Most induced mutations determine highly abnormal patterns (for reviews, see Frankel, 1989; Jerka-Dziadosz and Beisson, 1990).

Moreover, most spontaneous variants are likely to be strongly counterselected in nature, since they show either exceptionally low fission rates or exceptionally high postmating mortality. The fvtd variant does not seem to be altered in fission rate, a rather unexpected result, since it suggests that foraging activity, a vital function, is to a large extent uncorrelated with the FVT pattern; it must be admitted, however, that this conclusion may not be valid in natural conditions, where food is much scarcer than in laboratory cultures. The capacity for uniting with a mating partner is also normal. However, the experimental results indicate that the futd trait is associated with a very high mortality rate in exconjugants. The identification of the critical stage of the postmating sequence will be the aim of a further experimental study.

The rarity of genetically determined morphological variants in a natural population is well accounted for by such counterselection. When a variant phenotype is controlled by a single recessive allele, the frequency of this allele is necessarily very low so that the homozygous clones are exceptional. In laboratory conditions, inbreeding occurs, either spontaneously as a consequence of small population size or according to some experimental design, resulting in an increase of homozygote frequencies and favouring the detection of variants. The known morphological mutants of Paraurostyla weissei were discovered in this manner: the recessive alleles were present in a pond population. As for a polygenically determined trait the situation may be somewhat different. The fvtd variant has been isolated from a laboratory population in which genetic exchanges took place between previously separate gene pools, since the founder clones had been collected from geographically distant areas; possibly it was generated by recombination between these gene pools, though in a given locality the full gene set able to determine the fvtd phenotype would never be present. In the first situation some genetic load is associated with the variant in the populations where the recessive allele is present. In the second situation there is no genetic load in any population, and the genetic basis for the expression variant may be found only at the level of the whole species.

It appears from this discussion that nothing is known of how some of the characters which are currently used for species diagnoses are genetically determined.

This conclusion may be compared to the ideas expressed by Frankel (1983). He suggested a mode of speciation in which the primary event would be the fixation in a population of a mutation responsible for a shift in life habits, for instance adaptation to a new ecological niche. Such a population is expected to display some degree of reproductive isolation from the bulk of the species and to be submitted to new selective pressures resulting in sequential fixation of other mutations in such a way that a new species emerges which differs from the ancestral 
one by several genes. This model does not imply a major morphological effect of the primary mutation and, according to Frankel, the morphological divergence is likely to proceed slowly, on a polygenic basis. It implies, however, that some singlegene or oligogenically determined variant morphological traits are at least tolerated by natural selection. The variants which have been described or discussed in the present paper are not tolerated. Presently available data are far too restricted to conclude that tolerated variants do not exist. They nevertheless suggest that a given morphological pattern is controlled by a rather large array of genes with very complex intergenic interactions, in such a way that a change even at the level of a single gene is likely to severely disturb these interactions; it is thus suspected that a new tolerated morphological pattern can be generated only by a dramatic repatterning of the whole genic system. Further research is undoubtedly necessary in order to find new naturally occurring morphological variants and assess their fitness: this will allow an evaluation of the evolutionary potentialities of intraspecific morphological diversity.

\section{REFERENCES}

Borror AC (1972) Revision of the order Hypotrichida (Ciliophora, Protozoa). $J$ Protozool 19, 1-23

Chatton E, Lwoff A (1930) Imprégnation, par diffusion argentique, de l'infraciliature des Ciliés marins et d'eau douce, après fixation cytologique, et sans dessication. $C R$ Soc Biol 104, 834-836

Curds CR (1975) A guide to the species of the genus Euplotes (Hypotrichida, Ciliatea). Bull Br Mus Nat Hist (Zool) 28, 1-61

Dubielecka B, Jerka-Dziadosz M (1989) Defective spatial control in patterning of microtubular structures in mutants of the ciliate Paraurostyla. I. Morphogenesis in multi-left-marginal mutant. Eur J Protistol 24, 308-322

Foley JC (1943) A protargol method for staining nerve fibers in frozen and celloidin sections. Stain Technol 18, 27-33

Frankel J (1973a) A genically determined abnormality in the number and arrangement of basal bodies in a ciliate. Dev Biol 30, 336-365

Frankel J (1973b) Dimensions of control of cortical patterns in Euplotes: the role of preexisting structure, the clonal life cycle, and the genotype. J Exp Zool 183, 71-84 Frankel J (1983) What are the developmental underpinnings of evolutionary changes in protozoan morphology? In: Development and Evolution (Goodwin BC, Holder N, Wylie CG, eds) Cambridge Univ Press, Cambridge, 279-314

Frankel J (1989) Pattern Formation. Ciliate Studies and Models. Oxford University Press, Oxford

Frankel J, Heckmann K (1968) A simplified Chatton-Lwoff silver impregnation procedure for use in experimental studies with ciliates. Trans Am Microsc Soc 87, 317-321

Gates MA (1978a) Cirral patterns of cirrotype 9 Euplotes (Hypotrichida, Ciliophora). Protistologica 14, 125-132

Gates MA (1978b) Morphometric variation in the hypotrich ciliate genus Euplotes. $J$ Protozool 25, 338-350 
Génermont $J$ (1961) Déterminants génétiques macronucléaires et cytoplasmiques contrôlant la résistance au chlorure de calcium chez Paramecium aurelia (souche 90, variété 1). Ann Génét 3 (1), 1-8

Génermont J, Machelon V, Tuffrau M (1976) Données expérimentales relatives au problème de l'espèce dans le genre Euplotes (Ciliés Hypotriches). Protistologica 12, 239-248

Génermont J, Machelon V, Demar C (1985) The "vannus" group of genus Euplotes: sibling species and related forms; evolutionary significance and taxonomical implications. Atti Soc Toscana Sci Nat PV Mem Ser B 92, 53-65

Gianni A, Piras L (1990) Autoecological and molecular approach to the species problem in the Euplotes vannus-crassus-minuta group (Ciliophora, Hypotrichida) Eur J Protistol 26, 142-148

Heckmann K (1963) Paarungssystem und genabhängige Paarungstypdifferenzierung bei dem hypotrichen Ciliaten Euplotes vannus OF Müller. Arch Protistenk 106, 392421

Heckmann K (1964) Experimentelle Untersuchungen an Euplotes crassus. I. Paarungssystem, Konjugation und Determination der Paarungstypen. $Z$ Vererbungsl 95, 114-124

Heckmann K, Frankel J (1968) Genic control of cortical patterns in Euplotes. J Exp Zool 168, 11-38

Jerka-Dziadosz M (1989) Defective spatial control of patterning of microtubular structures in mutants of the ciliate Paraurostyla. II. Spatial coordinates in a double recessive mutant. Eur J Protistol 24, 323-335

Jerka-Dziadosz M, Banaczyk IA (1983) Cell shape, growth rate and cortical pattern . aberrations in an abnormal strain of the hypotrich ciliate Paraurostyla weissei. Acta Protozool 22, 139-156

Jerka-Dziadosz M, Dubielecka B (1985) Transmission of a genetic trait through total conjugation in a hypotrich ciliate Paraurostyla weissei. Genetic basis of the multi-left-marginal mutant. Genet Res Camb 46, 263-271

Jerka-Dziadosz M, Beisson J (1990) Genetic approaches to ciliate pattern formation; from self-assembly to morphogenesis. Trends Genet 6 (2), 41-45

Jerka-Dziadosz M, Muszynska K, Frontczak M (1989) Genetic analysis of ciliary pattern mutants in Paraurostyla weissei. Acta Protozzol 13, 309-322

Kaczanowski A (1975) A single-gene-dependent abnormality of adoral membranelles in Tetrahymena pyriformis, syngen 1 (species 1) ciliates. J Exp. Zool 196, 215-230

Laloë F (1979) Contribution à l'étude de la variabilité intraspécifique pour le nombre de cinéties dorsales et de cirres caudaux chez une espèce du complexe Euplotes vannus (Ciliés Hypotriches) Arch Zool Exp Gén 120, 109-129

Machelon V, Génermont J, Dattée Y (1984) A biometrical analysis of morphological variation within a section of genus Euplotes (Ciliata, Hypotrichida), with special reference to the $E$ vannus complex of sibling species. Origins of Life 13, 249-267 Müller OF (1786) Animalcula infusoria fluviatilia et marina. Havniae et Lipsiæ Nobili R (1964) Coniugazione ibrida tra specie di Euplotes (Ciliata, Hypotrichida) Boll Zool 31, 1338-1348

Nobili R (1966) Mating types and mating type inheritance in Euplotes minuta Yocom (Ciliata, Hypotrichida). J Protozool 24, 38-41 
Orias E, Flacks M (1975) Macronuclear genetics of Tetrahymena. I. Random distribution of macronuclear gene copies in $T$ pyriformis, syngen 1. Genetics 79 , 187-206

Schlegel M, Kramer M, Hahn K (1988) Taxonomy and phylogenetic relationship of eight species of the genus Euplotes (Hypotrichida, Ciliophora) as revealed by enzyme electrophoresis. Eur J Protistol 24, 22-29

Schliwa M, Van Blerkom J (1981) Structural interaction of cytoskeletal components. $J$ Cell Biol 90, 222-235

Sonneborn TM (1937) Sex, sex inheritance and sex determination in Paramecium aurelia. Proc Natl Acad Sci USA 23, 378-395

Sonneborn TM (1974) Tetrahymena pyriformis. In: Handbook of Genetics (King $\mathrm{RC}$, ed) Plenum Press, New York, vol 2, 433-467

Sonneborn TM (1975) The Paramecium aurelia complex of fourteen sibling species. Trans Am Microsc Soc 94, 155-178

Sonneborn TM (1977) Genetics of cellular differentiation: stable nuclear differentiation in eucaryotic unicells. Annu Rev Genet 11, 349-367

Tuffrau M (1960) Révision du genre Euplotes, fondée sur la comparaison des structures superficielles. Hydrobiologia 15, 1-77

Tuffrau M (1967) Perfectionnements et pratique de la technique d'imprégnation au protargol des Infusoires ciliés. Protistologica 3, 91-98

Tuffrau M, Tuffrau H, Génermont J (1976) La réorganisation infraciliaire au cours de la conjugaison et l'origine du primordium buccal dans le genre Euplotes. $J$ Protozool 23, 517-523

Valbonesi A, Ortenzi C, Luporini P (1988) An integrated study of the species problem in the Euplotes crassus-vannus-minuta group. J Protozool 35, 38-45

Wichterman R (1967) Mating types, breeding system, conjugation and nuclear phenomena in the marine ciliate Euplotes cristatus Kahl from the gulf of Naples. $J$ Protozool 14, 49-58

Wright S (1934a) An analysis of variability in number of digits in an inbred strain of guinea pig. Genetics 19, 506-536

Wright S (1934b) The results of crosses between inbred strains of guinea pig differing in number of digits. Genetics 19, 537-551 